\title{
Design and Analysis of Spur Gear Pair with Various Materials
}

\author{
S. Prabhakaran \\ Department of Mechanical Engineering, AMET University, Chennai, India
}

\begin{abstract}
The design and analysis of a spur equip is examined in this study. The goad outfit utilized as a part of BMW K75 engine bicycle of material SAE 9310 is chosen. Slant outfit has applications, for example, these need goad apparatuses to turn the corner from the interior burning motor to the back drive adapt. These riggings should ordinarily work at to great degree high rotational speeds and convey high power levels. The material is changed with flexor with these troublesome working conditions an enhanced explanatory capacity is principal to expanding security and unwavering quality. Likewise, writing on the examination and testing of goad riggings has been exceptionally meager in contrast with that for typical apparatuses. The spur apparatus is displayed and subjected to investigation and the variety in result is plotted.
\end{abstract}

Key words: Design, analysis, spur gear, comparison, various materials, flexor

\section{INTRODUCTION}

A vital piece of a shaft drive is dependably been a rigging. The pole drives incorporates angle apparatuses, shafts and heading amassed in a shut greased up lodging and it is broadly utilized as a part of the transmission framework (Artoni et al., 2008). They are accessible in a wide range as far as sizes, limits and speed proportions (Gabiccini et al., 2012). A silent operation is the most essential thing in any apparatus so all around characterized qualities of the rigging framework has turned out to be important (Litvin and Fuentes, 2004). In the vehicle business more number of riggings is utilized when contrasted with different ventures, so, higher unwavering quality and lighter weight apparatuses are important considering the request of lighter autos. Goad gears have bended teeth. The teeth are framed along a winding edge to the cone pivot. The most generally utilized winding edge is $35^{\circ}$ with the incorporation of weight edge $20^{\circ}$ (Litvin et al., 2006). In goad equip the apparatuses draw in more continuously (Marciniec, 2003) (Fig. 1). The contact initiates toward one side of the tooth those increments until there is contact over the entire length of the tooth. This decreases the danger of tooth breakage and a smoother transmission of energy is likewise empowered (Marciniec, 2003). In this research paper described that the experimental and numerical simulation of magnetic pulses for joining of dissimilar

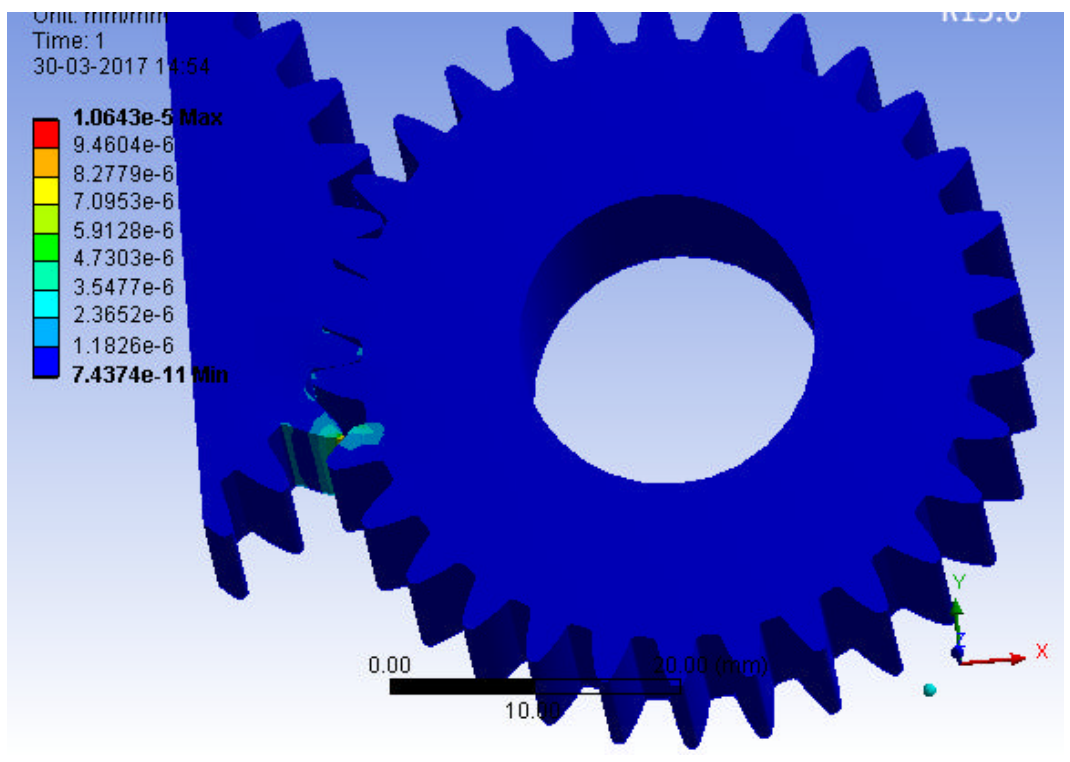

Fig. 1: 3D Model of gear 
materials with dissimilar geometry using electromagnetic welding process (Muthukumaran et al., 2017). Subsequently, goad riggings are calmer and it requires littler breadth for the transmission of same load than straight slant and the thermal properties of polypropylene/montmorillonite nano composites (Selvakumar and Manoharan, 2014). Dielectric and ferroelectric properties of non-linear optical single crystal: glycine-phthalic acid is presented in this study of Suresh, 2016). Analysis of optical and electrical studies of nonlinear optical crystal: potassium boro-oxalate (Sagadevan, 2016).

Modeling gear and pinion: At the point when the teeth of slant apparatus are slanted at an edge to the substance of the slant, these riggings are known as goad rigging. They run calmer in real life and have point contact. In the event that winding apparatus has bended teeth, however, with zero degree winding angles, it is known as zero slope equip. A correct hand goad rigging is one in which the external portion of a tooth is slanted in the clockwise bearing from the hub plane through the midpoint of the tooth as seen by an eyewitness taking a gander at the substance of the apparatus. A left hand goad rigging is one in which the external portion of a tooth is slanted in the counterclockwise bearing from the pivotal plane through the midpoint of the tooth as seen by an onlooker taking a gander at the substance of the apparatus. The created 3D Model is shown in the Fig. 1.

\section{MATERIALS AND METHODS}

Flexor: Flexor steel is a chromium-molybdenum-tungsten compound steel which shows a fine grain microstructure. All flexor steel warms are a vacuum degassed. Flexor is commonly supplied in an as moved condition. The dimension of the spur gear is shown in Fig. 2.

\section{Properties:}

. Density $(8.248 \mathrm{~g} / \mathrm{cm})$

. Poisson's ratio (0.144)

. Thermal conductivity $(57.5 \mathrm{~W} / \mathrm{mK})$

. Tensile strength $(542-780 \mathrm{MPa})$

- Modulus of elasticity (198 GPa)

\section{Existing material:}

- Material (steel SAE 9310)

. Density $\left(8.7-8.03 \mathrm{~g} / \mathrm{cm}^{\prime}\right)$

- Melting point $\left(1510^{\circ} \mathrm{C}\right)$

- Elastic modulus (187-215 GPa)

. Poisson's ratio $(0.25)$

. Tensile strength (428-580 MPa)

. Thermal conductivity $(47 \mathrm{~W} / \mathrm{m}-\mathrm{K})$

Quantity designation:

- Number of teeth z (2232)

- Hand of spiral (right)

- Transverse module $(0.984 \mathrm{~mm})$

- Pressure angle (28)

- Shaft angle (45)

- $\quad$ Spiral angle (2.514)

- Mean cone distance R $(28.25 \mathrm{~mm})$

. Face width b $(35 \mathrm{~mm})$

Analysis: The created spur gear model and pinion model are analyzed by the ANSYS Workbench Software. The steel material selected for analysis the gear and pinion which it is shown in the Fig. 3. The steel spur gear safety factor is 15 maximum. This factor safety of the gear is shown by the red color.

Mild steel: The total deformation is the important one for each and every component. The total deformation of mild steel gear and mild steel pinion are shown in the Fig. 4.

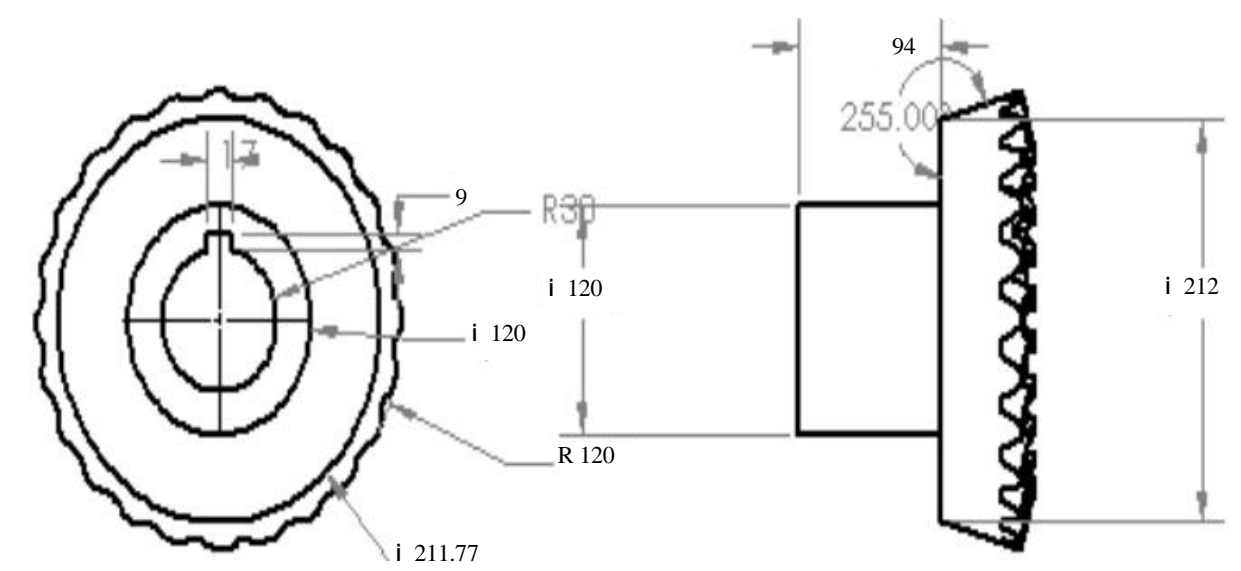

Fig. 2: Gear dimensions 


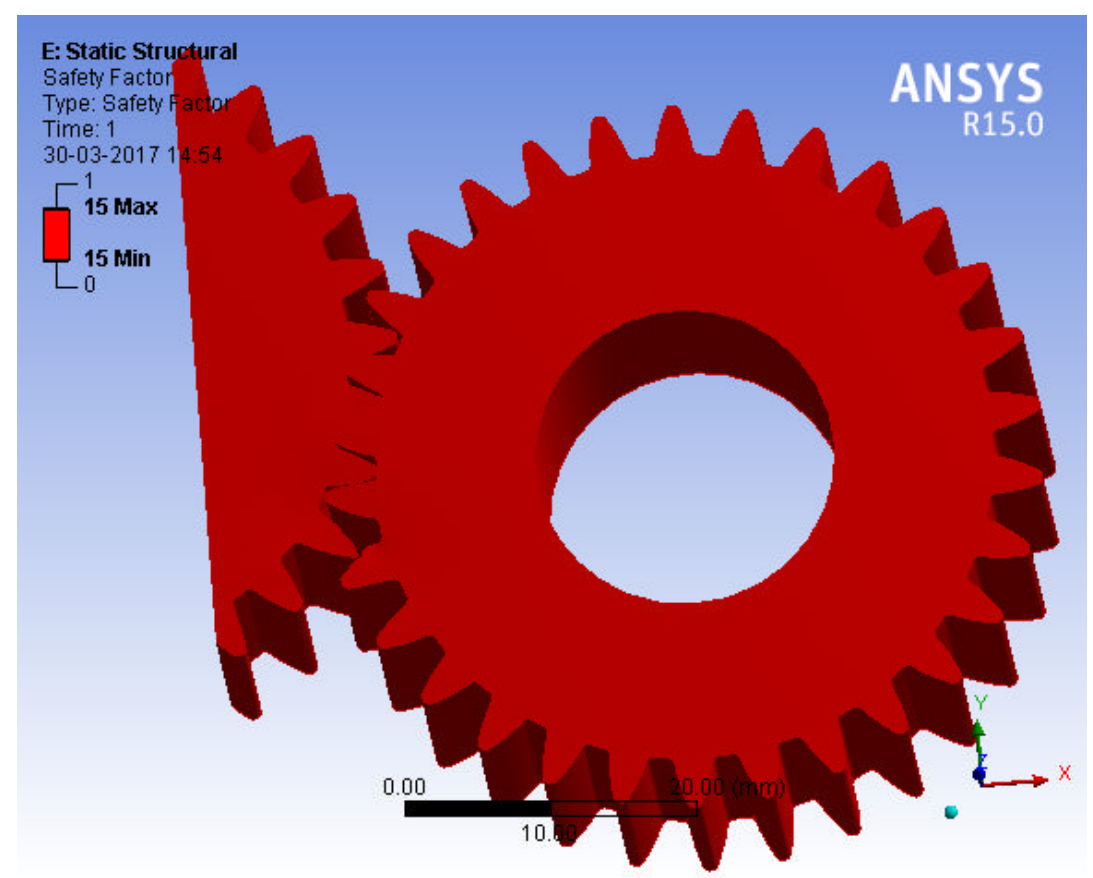

Fig. 3: Safety factor of steel

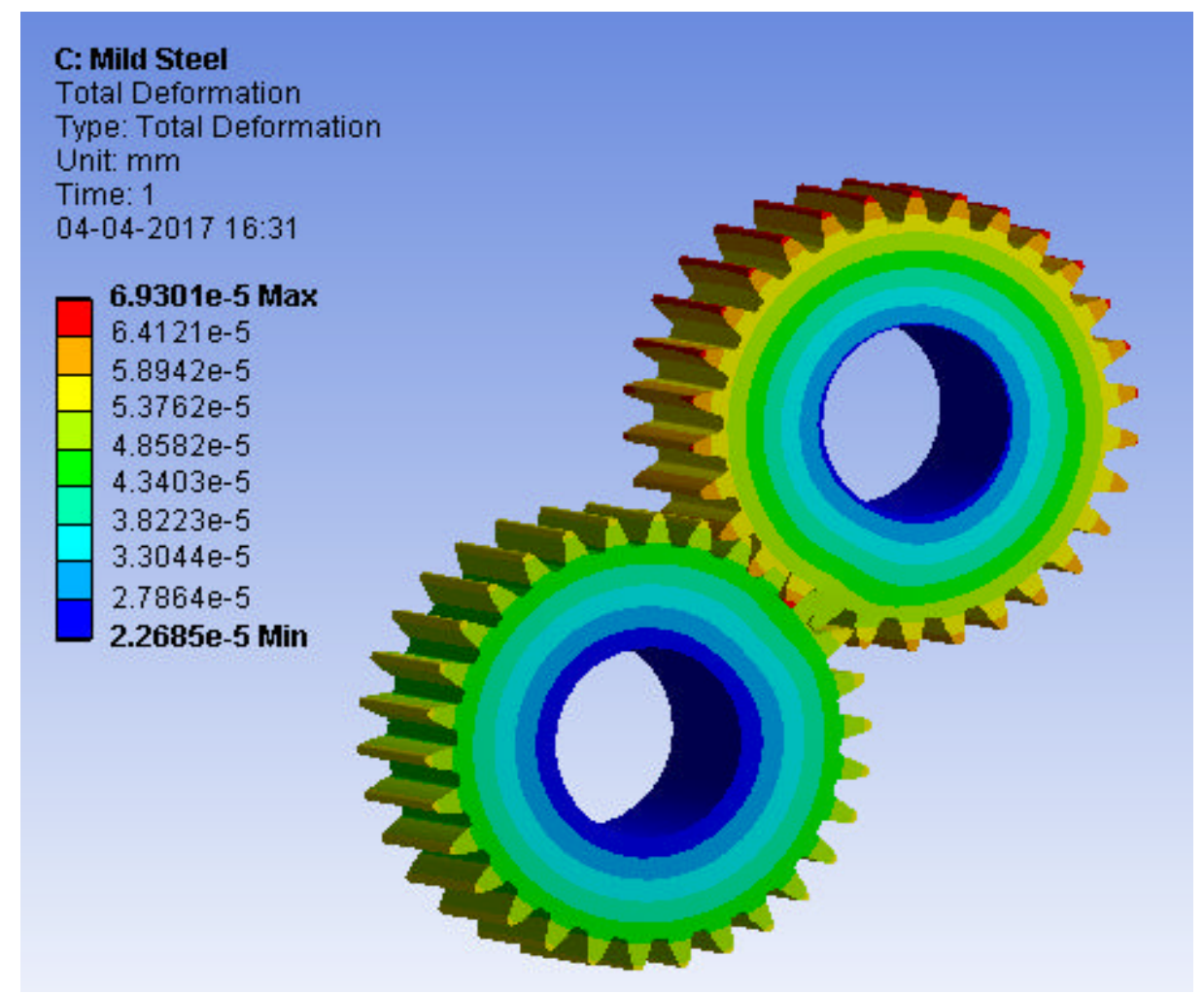

Fig 4: Deformation of mild steel

The maximum deformation is shown in the figure by the red color. The maximum deformation point of mild steel gear and pinion is $6.9301 \mathrm{e}-5 \mathrm{~mm}$. This value is shown in the left side of the above image. 


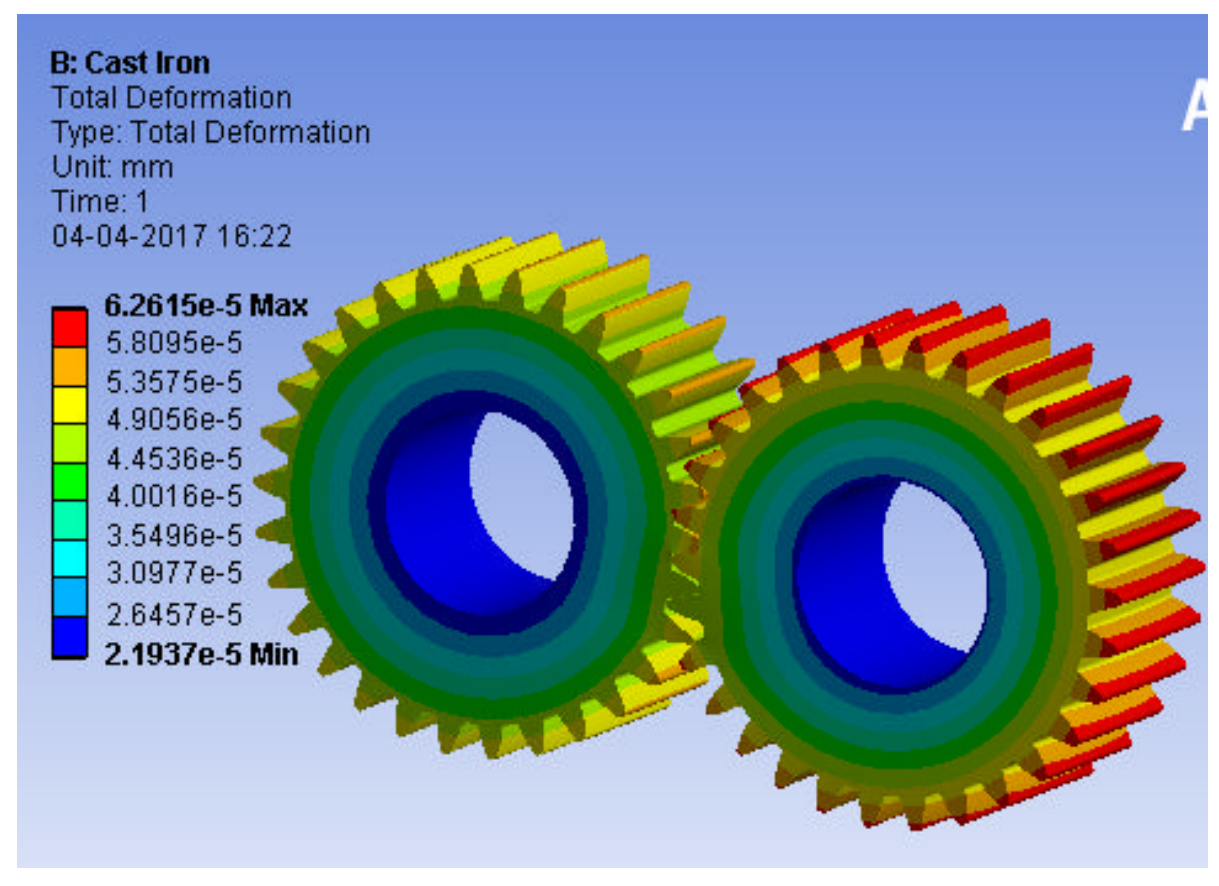

Fig. 5: Deformation of cast iron

Cast iron: The total deformation is the important one for each and every component. The total deformation of cast iron gear and cast iron pinion are shown in the Fig. 5. The maximum deformation is shown in the Fig. 5 by the red color. The maximum deformation point of mild steel gear and pinion is $6.2615 \mathrm{e}-5 \mathrm{~mm}$. This value is shown in the left side of the above image.

\section{RESULTS AND DISCUSSION}

The displacement values for mild steel spur gear is much less when compared to the steel spur gear when torque load is being applied. The three dimensional stress (Von misses Stress) values are comparatively very less for mild steel compared with cast iron spur gears The consumption of yield strength is very much less in the case iron spur gears when compared to the steel spur gears. From the modal analysis of three spur gears, it is understood that the natural frequency of mild steel spur gear is very high when compared to steel spur gears.

\section{CONCLUSION}

In this way, the current model of goad apparatus is displayed with existing dimension. The spur gear and pinion are successfully created by the SolidWorks Software and also the created solid model was successfully analyzed by the ANSYS Workbench
Software. In this study, the two different materials are used analysis the spur gear. The both material results are compared with each other. By the comparison the cast iron is suitable for the spur gear and pinion.

\section{REFERENCES}

Artoni, A., M. Gabiccini and M. Guiggiani, 2008. Nonlinear identification of machine settings for flank form modifications in hypoid gears. J. Mech. Des., 130: 112602-112610.

Gabiccini, M., A. Artoni and M. Guiggiani, 2012. On the identification of machine settings for gear surface topography corrections (DETC201147727). ASME J. Mech. Des., Vol. 134. 10.1115/1.4006002

Litvin, F.L. and A. Fuentes, 2004. Gear Geometry and Applied Theory. Cambridge University Press, Cambridge, UK.,.

Litvin, F.L., A. Fuentes and K. Hayasaka, 2006. Design, manufacture, stress analysis and experimental tests of low-noise high endurance spiral bevel gears. Mech. Mach. Theory, 41: 83-118.

Marciniec, A., 2003. Synthesis and Analysis of Meshing for Spur Gears. Rzeszow University, Rzeszow, Poland, 
Muthukumaran, S., A.S. Kumar, S.A. Vendan and S. Kudiyarasan, 2017. Experimental and numerical simulation of magnetic pulses for joining of dissimilar materials with dissimilar geometry using electromagnetic welding process. Intl. J. Appl. Electromagnet. Mech., 53: 237-249.

Sagadevan, S., 2016. Optical and electrical studies of nonlinear optical crystal: Potassium boro-oxalate. Optik Intl. J. Light Electron. Opt., 127: 5613-5621.
Selvakumar, V. and N. Manoharan, 2014. Thermal properties of polypropylene/montmorillonite nanocomposites. Indian J. Sci. Technol., 7: 136139.

Suresh, S., 2016. Growth, optical, dielectric and ferroelectric properties of non-linear optical single crystal: Glycine-phthalic acid. J. Electron. Mater., 11: 5904-5909. 